\title{
Deciphering the Binding of Natural Terpenoids to Mycobacterium tuberculosis Type III Polyketide Synthase18 (PKS18): An In-Silico Approach
}

\author{
Akanksha Sharma ${ }^{1}$, Mohammad Hayatul Islam ${ }^{1}$, Nida Fatima ${ }^{1}$, Tarun K. Upadhyay ${ }^{1}$, M. Kalim A. Khan ${ }^{2}$, \\ Upendra N. Dwivedi ${ }^{3}$, Rolee Sharma ${ }^{1 *}$ \\ ${ }^{1}$ Department of Biosciences, Integral University, Lucknow-226026, U.P., India. \\ ${ }^{2}$ Department of Bioengineering, Integral University, Lucknow-226026, U.P., India. \\ ${ }^{3}$ Department of Biochemistry, Bioinformatics Infrastructure Facility, Centre of Excellence in Bioinformatics, University of Lucknow, Lucknow-226007, \\ U.P., India.
}

\section{ARTICLE INFO \\ Article history: \\ Received on: 08/03/2018 \\ Accepted on: 12/04/2018 \\ Available online: 30/05/2018}

\section{Key words:}

Tuberculosis, terpenoids, molecular docking, ADMET and type III polyketide synthase 18 .

\begin{abstract}
Tuberculosis (TB) is a major cause of death across the globe and kills 1.5 million people per annum, thereby persisting as a challenge for the scientific community. Although the 'Directly Observed Treatment, Short Course' chemotherapy (DOTS) is an internationally recommended approach for TB, the treatment regimen is long and arduous, making patient compliance difficult. This has led to the occurrence of antibiotic confrontation, creating a need for the identity of novel drug lead(s) towards new targets identified in Mycobacterium tuberculosis (M.tb.). The current study was undertaken with this objective directed towards the identification of potential drug candidate(s) for TB therapy using an in silico approach against PKS18, a mycobacterial enzyme essential for its intracellular survival, pathogenicity and drug resistance. In the present study, 672 natural terpenoids from plants, algae, bacteria, fungi and marine sponges were compiled and put through in silico pharmacokinetic analysis in term of absorption, distribution, excretion, and toxicity (ADMET) to explore their drugability properties. Pharmacokinetic analyses revealed that 18 plant-derived and 1 marine sponge-derived natural compounds satisfy all the ADMET criterion and also those of Lipinski's Rule of Five. These natural compounds docked successfully within the active site of type III polyketide synthase18 (PKS18) and exhibited low binding energy indicating high affinity. In addition, docking was also performed with commercially available first-line TB drugs including rifampicin, isoniazid, ethambutol, and pyrazinamide to compare the binding efficacy with that of the selected natural compounds. Of the compounds tested, vulgarin showed the best docking profile, followed by alisiaquinone A, 12-Deoxyphorbol-13-angelate-20-acetate and cynaropicrin.
\end{abstract}

\section{INTRODUCTION}

Tuberculosis (TB) is a chronic disease caused by the bacillus Mycobacterium tuberculosis (M.tb.) remains an important underlying cause of death from an infectious disease globally after the acquired immunodeficiency syndrome (AIDS). According to Center for Disease Control (CDC) two billion people, one-fourth

\section{${ }^{*}$ Corresponding Author}

Dr. Rolee Sharma, Associate Professor, Department of Biosciences, Integral University, Lucknow-226026, UP., India.

E-mail:rsharma@iul.ac.in of the world's populace are inflamed with TB global, with more than 10 million becoming ill from the disease and at risk for transmitting TB to others (WHO, 2017). In 2016, 6.3 million new instances of TB were accounted (up from 6.1 million in 2015) and there were an estimated 1.3 million TB deaths among without HIV people (down from 1.7 million in 2000) and an additional 374 000 deaths among with HIV people (Global Tuberculosis Report, 2017). This exacerbated condition is mainly due to three reasons, HIV-TB co-existence (amounting to 1.2 million of the 9.6 million annual cases), the failure of BCG vaccine to combat TB and the appearance of drug resistant (MDR and XDR tuberculosis) strains. Most commonly used antimycobacterial agents in multidrug 
combinations due to the frequent inception of resistance, which is frequently perceived as a consequence of poor patient compliance and incomplete treatment of vigorous infections through the long course of treatment required with most therapeutic regimens. Now there is a need to discover and develop safe and natural anti-TB drugs, particularly to combat drug resistance and improve the treatment of TB. Thus, the discovery of anti-TB agents that target essential pathways in M.tb. is crucial for effective short-term TB therapy and treatment of resistant M.tb. strains.

A number of key enzymes involved in unique metabolic pathways, specific to the mycobacterial cell wall biogenesis and physiological functions have been identified to serve as persuasive targets for the design of novel anti-TB agents (Xiuming et al., 2003). Polyketide synthases (PKSs) form a huge group of multifunctional proteins associated with the biosynthesis of divergent classes of natural products. In mycobacteria, polyketide synthases (PKSs) have been allied to the biosynthesis of composite lipids, and several PKS mutants show fading in virulence properties of mycobacteria (Barry, 2001). M.tb. PKS18 is a homodimeric enzyme and each monomeric subunit contains 393 amino acid residues with a molecular weight of $84.064 \mathrm{kDa}$ (Rukmini et al., 2004). M.tb PKS18 and alfalfa chalcone synthase exhibit $42 \%$ sequence homology (Saxena et al., 2003). The PKS18 catalyzes the formation of $\alpha$-pyrone products by incorporating unusual long-chain starter substrates. The high specificity of PKS18 for long-chain starter substrates is unprecedented in the chalcone synthase family of condensing enzymes (Saxena et al., 2003). Goyal et al. (2008) investigated the molecular basis of starter molecule specificity of fungal PKSIII from Neurospora crassa using mutational studies and compare it with similar type III PKS proteins, By using very long chain acyl-CoA starter substrates PKSIII protein synthesis 5-n-alkylresorcinol that prove their promiscuous starter unit specificity (Goyal et al., 2008). PKS18 from M.tb. displays a broad specificity for starter substrate, aliphatic long-chain acyl-coenzyme $\mathrm{A}$ (acyl-CoA) units $\left(\mathrm{C}_{6}-\mathrm{C}_{20}\right)$ to produce tri and tetraketide pyrones (Saxena et al., 2003). It is proposed that PKSs in conjunction with fatty acid synthases (FASs) generate diverse, unusual lipids that constitute the complex cell wall of this microorganism (Brennan, 2003). M.tb. exploits polyketide biosynthetic enzymes to synthesize complex lipids, many of which are essential for its survival, endurance, virulence and drug confrontation (Saxena et al., 2003; Gokhale et al., 2007).

In addition, a recent study has demonstrated a crucial role of the polyketide quinones (PkQs) produced by type III polyketide synthases using fatty acyl-CoA precursors during mycobacterial microaerophilic respiration. The $\mathrm{PkQs}$ have been recently discovered to maintain cellular bioenergetics in oxygen-deficient niches and are expressed in biofilms. The PKS thus play a crucial role in supporting mycobacterial survival in hypoxia (Anand et al., 2015). Conceptually, targeting PKS18 is expected to disrupt the biosynthesis of long-chain $\alpha$-pyrones and consequently, inhibit the generation of diverse unusual lipids and leads to rapid death of M.tb. in hypoxia condition.

Computational approaches had been developed and generally utilized to pharmacology hypothesis progress and testing. These techniques have been often used by researchers to innovate and optimize new ligands/metabolites/compounds with a higher affinity towards a target, the clarification of ADMET properties as well as physicochemical characterization (Vijayalakshmia et al., 2016). Molecular docking studies predict the ideal orientation of one molecule to a second when bound to each other, to form a stout complex. Study of the ideal orientation of complex is used to compute the strength of association or binding affinity of the molecules, for example, scoring functions (Ewing et al., 2001; Bursulaya et al., 2003). The three-dimensional structure of the protein and a database of potential ligands serve as inputs to a docking application. The set molecular docking algorithms in the program, fit both protein and ligand molecules together in complementary fashions. The process has attracted increasing attention as a way to predict the geometries of bimolecular complexes (Irawin et al., 1994). The present study has been carried out to test the efficiency of the naturally occurring terpenoids from different origins (plants, algae, bacteria, fungi and marine sponges) against PKS18, using ADMET and Molecular Docking studies so as to explore potential drug lead(s). The work plan with the different approaches used in this study is shown in Figure 1.

\section{MATERIALS AND METHODS}

\section{Software required}

Cygwin-a (data storage program) downloaded from www.cygwin.com, MGL (Molecular Graphics Laboratory) tools AutoDock4.2 boot up from www.scripps.edu, Discovery studio (DS) visualize 3.0 downloaded from www.accelerys.com, Accelrys draw download by www.accelrys.com, Python 2.5 downloaded from www.python.org.

\section{Preparation of ligand}

Natural terpenoids from different sources (plants, algae, bacteria, fungi and marine sponges) were composed from accessible literature and from a databases of plant secondary metabolites, namely, a naturally occurring plant-based anticancer compound activity target database (NPACT) (Denis et al., 2008; Mangal et al., 2013). Chemical properties and mol files of the selected terpenoids were downloaded from the NCBI-PubChem database (http//pubchem.ncbi.nlm.nih.gov/). Chemical structures of vulgarin (CID 94253), alisiaquinone A (CID 24970867), 12-Deoxyphorbol-13-angelate-20-acetate (CID 6444377) and cynaropicrin (CID 119093) compounds are shown in Figure 2. In addition commercially available first-line TB drugs including Isoniazid (CID 3767), Rifampicin (CID 5381226), Ethambutol (CID 14052) and Pyrazinamide (CID 1046) were considered as controls for the study.

\section{Pharmacokinetic analyses}

\section{ADME/Tox properties}

ADME/Tox profile of the terpenoids and standard drugs were calculated by an online server PreADMET (http://preadmet. bmdrc.org/). The server computes pharmacokinetic attributes as Human Intestinal Absorption (HIA), cell permeability Caco-2 in vitro $(\mathrm{PCaCO} 2)$, cell permeability of Maden Darby Canine Kidney (PMDCK), skin permeability (PSkin), Plasma Protein Binding (PPB) and the diffusion of the blood-brain barrier (CBrain/ CBlood), and toxicological attributes such as: mutagenicity and carcinogenicity (Yamashita et al., 2000). 


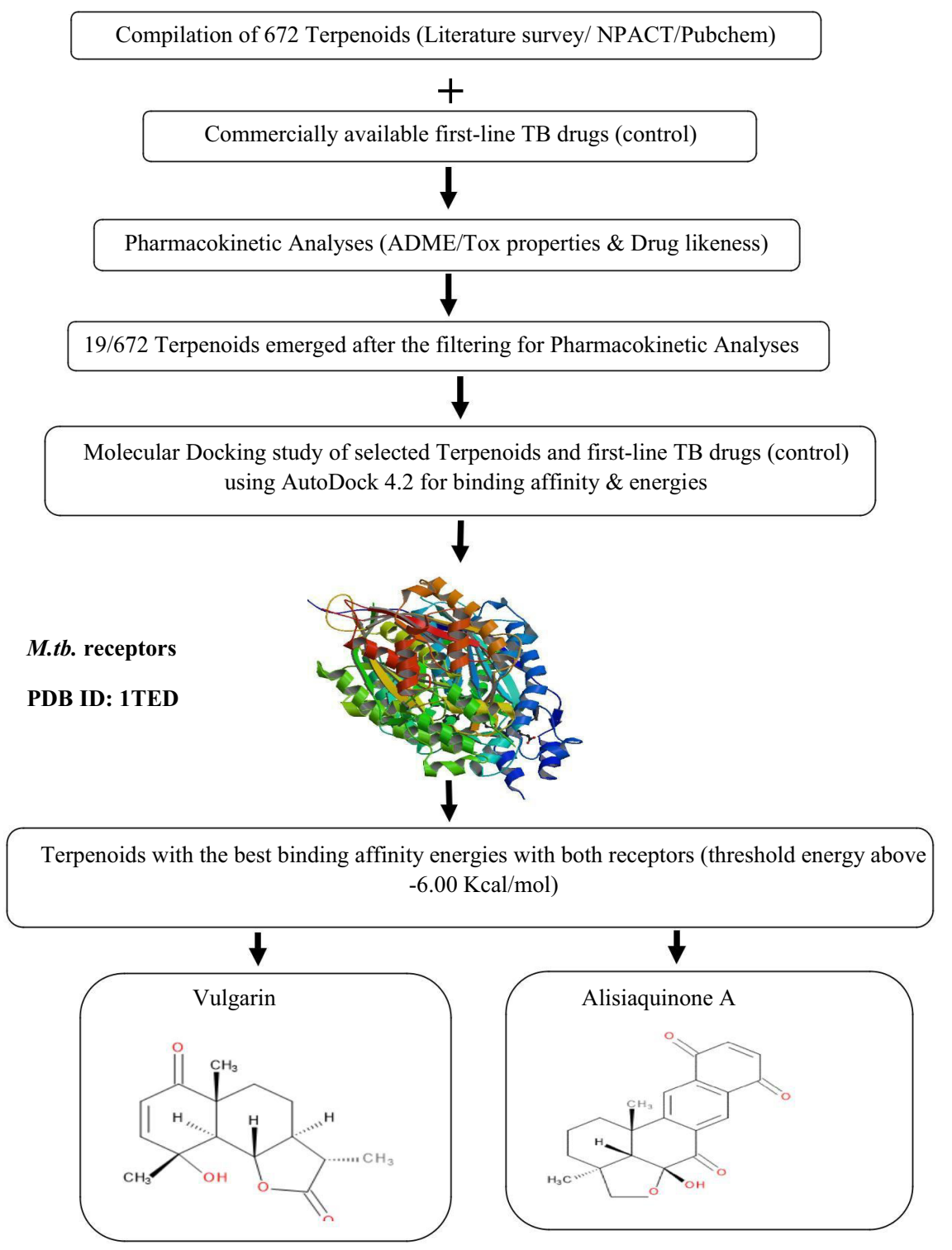

Fig. 1: Graphical representation of the different approaches used in this study.

Drug likeness

Drugability of the screened out terpenoids and drugs after ADME/Tox prediction were analyzed for Lipinski's rule of five, using Discovery studio, by evaluating four properties, namely, H-bond donor, H-bond acceptor, molecular weight, and Alog $P$ (partition coefficient) of the assumed therapeutic molecules (Lipinski et al., 2001).

\section{Macromolecule preparation}

The 3-D structure of target protein PKS 18 (PDB ID 1TED) of M.tb. was retrieved from the Protein Data Bank (RCSB PDB, http://www.pdb.org) (Anchana, 2012). The PDB file was prepared using the software Accelrys Discovery Studio (Version 3.0, Accelrys Software Inc.). All bound substances (water molecules, heteroatoms, ligands, and cofactors) were removed from the crystal structure. The binding site residues for PKS 18 were identified from previous studies (Anchana, 2012).

\section{Molecular docking analysis}

Molecular docking software Autodock 4.2 was used to study target-ligand interaction, which is built on Lamarckian Genetic Algorithm (for the best conformers and maximum of 10 conformers were considered for each compound) for estimating binding energy and inhibitory constant (Morris et al., 2009). For target PKS18, the grid was prepared with $90 \times 90 \times 90(\mathrm{x}$, $\mathrm{y}$, and $\mathrm{z}$ ), points, and other parameters were set as default for molecular docking. Molecular docking runs were performed on Intel@Core ${ }^{\mathrm{TM}} \mathrm{i} 5-7400 \mathrm{CPU} @ 3.00 \mathrm{GHz}$ of HP info system origin, with 8 GB DDR RAM. AutoDock 4.2 was compiled and run under Windows 7 professional operating system. The docked complex in the lowest energy cluster was appraised for all further interaction studies. The binding energy and inhibition constant (Ki) are expressed as $\mathrm{kcal} / \mathrm{mol}$ and micromolar $(\mu \mathrm{M})$, respectively. 


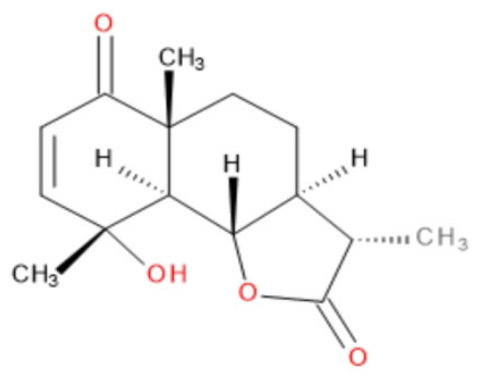

A

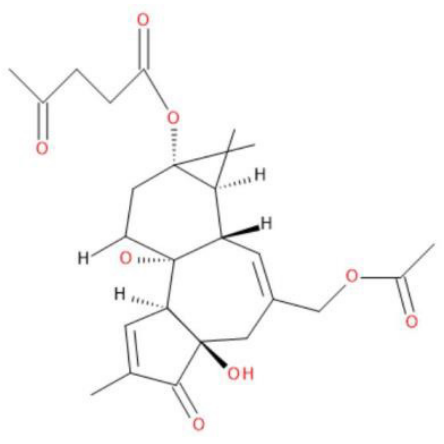

C

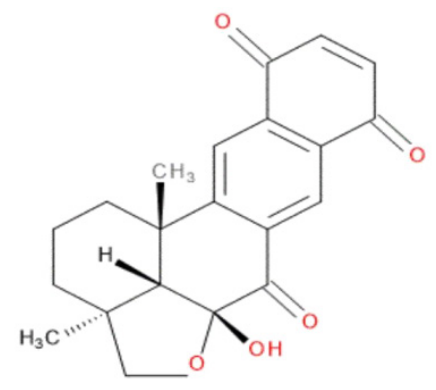

B

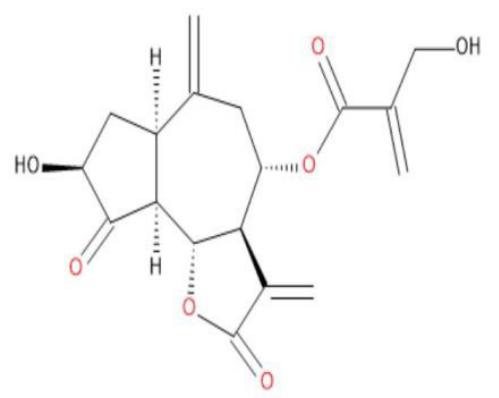

D

Fig. 2: Chemical structure of terpenoids; (A) Vulgarin (B) Alisiaquinone A, (C) 12-Deoxyphorbol-13-angelate-20-acetate and (D) Cynaropicrin.

\section{RESULTS AND DISCUSSION}

\section{Pharmacokinetic and toxicological properties}

\section{ADME/Tox based screening}

Currently, the discovery of new drugs is based on the pharmacokinetic process, to check the impact of compounds/drugs on the biological system (Avdeef et al., 2018). The results of ADME/ Tox test were used to observe the absorption of compounds/drugs in human intestine, permeability in human epithelial colorectal cells and Madin-Darby Canine Kidney cells (PCaco2 and PMDCK), permeability in skin (Pskin), plasma protein binding (PPB) affinity and permeability of the blood-brain barrier $\left(\mathrm{C}_{\text {Brain }} / \mathrm{C}_{\text {Blood }}\right)$. The toxicological test in terms of mutagenicity and carcinogenicity of the top four compounds are shown in Table 1.

A total of 672 were natural terpenoids subjected to in silico ADME/Tox analyses to investigate their pharmacokinetic properties. Pharmacokinetic analyses revealed that 18 plantderived and 1 marine sponge-derived natural compounds fulfill all the ADMET descriptors but the HIA results of four terpenoids were near about $100 \%$, indicating their classification as good absorption in human intestine. Permeability to human epithelial colorectal cells (PCaco-2) enables the evaluation of the potential for intestinal absorption and passive transport of compounds/ drugs. In a given time zone the dissolve and absorbed fraction (dissolution-absorption relationship) of the drug can be predicted by this information (Zhao et al., 2001). Table 1 shows the PCaco-2 values for selected terpenoids, that have been ranked as average permeability (value $<70 \mathrm{~nm} / \mathrm{sec}$ ) and high permeability $(>70$ $\mathrm{nm} / \mathrm{sec})$. It is worth mentioning that all the compounds exhibited a medium permeability, the values for top four compounds being: $18.3127 \mathrm{~nm} / \mathrm{sec}$ (for Cynaropicrin), $25.4601 \mathrm{~nm} / \mathrm{sec}$ (for Alisiaquinone A), $20.8179 \mathrm{~nm} / \mathrm{sec}$ (for 12-Deoxyphorbol13-angelate-20-acetate) and $20.7580 \mathrm{~nm} / \mathrm{sec}$ (for Vulgarin), respectively.

The prediction of PMDCK is used for canine kidney cells permeability is as a mark of fast screening tool of permeability (Horie et al., 2003). All compounds exhibited moderate PMDCK values, as shown in Table 1. The skin permeability (Pskin) forecast for all compounds exhibited negative values, indicating that for all compounds cannot be used transdermally. The values for PPB in Table 1 indicate that these compounds do not bind strongly to plasma proteins, thereby promising for good pharmacological effects. This is because, only the unbound fraction of the drug (unbound to plasma protein) is free to bind with the target to prove their pharmacological effects (Smith et al., 2001). The BBB values are classified according to Ma et al. (2005).

All tested compounds presented lower values than $1\left(\mathrm{C}_{\text {Brain }} / \mathrm{C}_{\text {Blood }}>1\right)$, being considered inactive in CNS, these values provide evidence of the nontoxic effect of terpenoids in the CNS. The mutagenicity and carcinogenicity evaluation of all four terpenoids by preADMET online server ( $\mathrm{Ma}$ et al., 2005; Woo, 2003) showed that they were non-mutagenic and non-carcinogenic while the pharmacokinetic analysis of standard drugs revealed that Rifampicin and Isoniazid are mutagenic while Ethambutol observed as mutagenic as well as carcinogenic. Rifampicin and Isoniazid showing the inhibition 
of Cytochrome P450 2D6, Drugs those inhibit CYP2D6 activity are likely to grow the plasma concentrations of certain medications, and in some cases, adverse outcomes will occur (Table 1).

Table 1. Pharmacokinetic and Toxicological (ADME/Tox) properties of top four terpenoids and drugs.

\begin{tabular}{|c|c|c|c|c|c|c|c|c|c|c|}
\hline \multirow{3}{*}{ S. No. } & \multirow{3}{*}{ Compound name } & \multirow{3}{*}{$\begin{array}{l}\text { Mutagenicity } \\
\text { (Ames test) }\end{array}$} & \multicolumn{2}{|l|}{ Toxicity } & \multicolumn{3}{|l|}{ Absorption } & \multicolumn{2}{|c|}{ Distribution } & \multirow{3}{*}{$\begin{array}{c}\text { Metabolism } \\
\text { CYP2D6 }^{\mathrm{a}}\end{array}$} \\
\hline & & & & & PCaco-2 $^{\mathrm{b}}$ & PMDCK $^{\mathrm{c}}$ & Pskin $^{\mathrm{d}}$ & & $\mathbf{B B B}^{\mathrm{f}}$ & \\
\hline & & & Carcinogenicity & HIA \% & $(\mathrm{nm} / \mathrm{sec})$ & $(\mathrm{nm} / \mathrm{sec})$ & $(\mathrm{nm} / \mathrm{sec})$ & PPB \% & $\left(\mathrm{C}_{\text {Brain }} / \mathrm{C}_{\text {Blood }}\right)$ & \\
\hline 1. & Vulgarin & Non-mutagenic & Non-carcinogenic & 98.910 & 20.7580 & 27.7768 & -3.54441 & 60.462 & 0.573169 & Non-inhibitor \\
\hline 2. & Alisiaquinone A & Non-mutagenic & Non-carcinogenic & 99.744 & 25.4601 & 26.55957 & -4.09551 & 71.693 & 0.00830 & Non-inhibitor \\
\hline 3. & $\begin{array}{l}\text { 12-Deoxyphorbol-13- } \\
\text { angelate-20-acetate }\end{array}$ & Non-mutagenic & Non-carcinogenic & 99.406 & 20.8179 & 26.22335 & -1.6556 & 68.395 & 0.057335 & Non-inhibitor \\
\hline 4. & Cynaropicrin & Non-mutagenic & Non-carcinogenic & 99.481 & 18.3127 & 26.28359 & -3.44862 & 74.739 & 0.041162 & Non-inhibitor \\
\hline 5. & Rifampicin & Mutagenic & Non-carcinogenic & 66.865 & 3.50468 & 249.495 & -4.50376 & 22.3782 & 0.482248 & Inhibitor \\
\hline 6. & Isoniazid & Mutagenic & Non-carcinogenic & 87.105 & 19.4963 & 0.810385 & -4.6289 & 1.60743 & 0.260629 & Inhibitor \\
\hline 7. & Ethambutol & Mutagenic & Carcinogenic & 87.450 & 16.437 & 119.558 & -4.24167 & 0.71143 & 0.153504 & Non-inhibitor \\
\hline 8. & Pyrazinamide & Non-mutagenic & Non-carcinogenic & 84.273 & 19.4872 & 0.04341 & -2.85118 & 63.5080 & 0.0641154 & Non-inhibitor \\
\hline
\end{tabular}

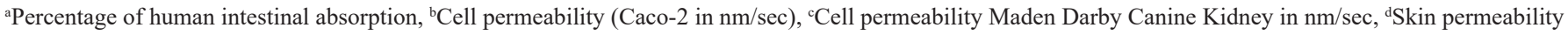
$(\mathrm{nm} / \mathrm{sec})$, ${ }^{\mathrm{e}}$ Percentage of plasma protein binding, ${ }^{\mathrm{f}} \mathrm{Blood}$ Brain Barrier $\left(\mathrm{C}_{\mathrm{Brain}} / \mathrm{C}_{\mathrm{Blood}}\right),{ }^{\mathrm{g}} \mathrm{Cytochrome} \mathrm{P} 4502 \mathrm{D} 6$ binding.

Table 2: Drugability of top four terpenoids and known inhibitor on the basis of Lipinski's rule of five.

\begin{tabular}{|c|c|c|c|c|c|c|}
\hline $\begin{array}{l}\text { S. } \\
\text { No. }\end{array}$ & Name of compound & Canonical SMILES & $\begin{array}{c}\text { H-bond } \\
\text { donor }(\leq 5)\end{array}$ & $\begin{array}{c}\text { H-bond } \\
\text { acceptor }(\leq 10)\end{array}$ & $\begin{array}{l}\text { Molecular weight } \\
(\mathrm{g} / \mathrm{mol})(\leq \mathbf{5 0 0})\end{array}$ & $\begin{array}{c}\operatorname{Alog} P \\
(\leq 5)\end{array}$ \\
\hline 1. & Vulgarin & $\mathrm{CC} 1 \mathrm{C} 2 \mathrm{CCC} 3(\mathrm{C}(\mathrm{C} 2 \mathrm{OC} 1=\mathrm{O}) \mathrm{C}(\mathrm{C}=\mathrm{CC} 3=\mathrm{O})(\mathrm{C}) \mathrm{O}) \mathrm{C}$ & 1 & 4 & 264.321 & 1.2 \\
\hline 2. & Alisiaquinone A & $\mathrm{CC} 12 \mathrm{CCCC} 3(\mathrm{C} 1 \mathrm{C}(\mathrm{C}(=\mathrm{O}) \mathrm{C} 4=\mathrm{C} 3 \mathrm{C}=\mathrm{C} 5 \mathrm{C}(=\mathrm{O}) \mathrm{C}=\mathrm{CC}(=\mathrm{O}) \mathrm{C} 5=\mathrm{C} 4)(\mathrm{OC} 2) \mathrm{O}) \mathrm{C}$ & 2 & 8 & 457.497 & 2 \\
\hline 3. & $\begin{array}{l}\text { 12-Deoxyphorbol-13- } \\
\text { angelate-20-Acetate }\end{array}$ & $\begin{array}{c}\mathrm{CC}=\mathrm{C}(\mathrm{C}) \mathrm{C}(=\mathrm{O}) \mathrm{OC} 12 \mathrm{CC}(\mathrm{C} 3(\mathrm{C}(\mathrm{C} 1 \mathrm{C} 2(\mathrm{C}) \mathrm{C}) \mathrm{C}=\mathrm{C}(\mathrm{CC} 4(\mathrm{C} 3 \mathrm{C}=\mathrm{C}(\mathrm{C} 4=\mathrm{O}) \mathrm{C}) \mathrm{O}) \\
\mathrm{COC}(=\mathrm{O}) \mathrm{C}) \mathrm{O}) \mathrm{C}\end{array}$ & 2 & 7 & 472.578 & 2.5 \\
\hline 4. & Cynaropicrin & $\mathrm{C}=\mathrm{C} 1 \mathrm{CC}(\mathrm{C} 2 \mathrm{C}(\mathrm{C} 3 \mathrm{C} 1 \mathrm{CC}(\mathrm{C} 3=\mathrm{C}) \mathrm{O}) \mathrm{OC}(=\mathrm{O}) \mathrm{C} 2=\mathrm{C}) \mathrm{OC}(=\mathrm{O}) \mathrm{C}(=\mathrm{C}) \mathrm{CO}$ & 2 & 6 & 346.379 & 0.6 \\
\hline \multirow[t]{2}{*}{5.} & Rifampicin & $\mathrm{CC} 1 \mathrm{C}=\mathrm{CC}=\mathrm{C}(\mathrm{C}(=\mathrm{O}) \mathrm{NC} 2=\mathrm{C}(\mathrm{C} 3=\mathrm{C}(\mathrm{C}(=\mathrm{C} 4 \mathrm{C}(=\mathrm{C} 3 \mathrm{C}(=\mathrm{O}) \mathrm{C} 2=\mathrm{CNN} 5$ & 6 & 15 & 822.953 & 4 \\
\hline & & $\begin{array}{c}\mathrm{CCN}(\mathrm{CC} 5) \mathrm{C}) \mathrm{C}(=\mathrm{O}) \mathrm{C}(\mathrm{O} 4)(\mathrm{OC}=\mathrm{CC}(\mathrm{C}(\mathrm{C}(\mathrm{C}(\mathrm{C}(\mathrm{C}(\mathrm{C} 1 \mathrm{O}) \mathrm{C}) \mathrm{O}) \mathrm{C}) \mathrm{OC}(=\mathrm{O}) \mathrm{C}) \mathrm{C}) \mathrm{OC}) \\
\mathrm{C}) \mathrm{C}) \mathrm{O}) \mathrm{O}) \mathrm{C}\end{array}$ & & & & \\
\hline 6. & Isoniazid & $\mathrm{C} 1=\mathrm{CN}=\mathrm{CC}=\mathrm{C} 1 \mathrm{C}(=\mathrm{O}) \mathrm{NN}$ & 2 & 3 & 137.142 & -0.7 \\
\hline 7. & Ethambutol & $\mathrm{CCC}(\mathrm{CO}) \mathrm{NCCNC}(\mathrm{CC}) \mathrm{CO}$ & 4 & 4 & 204.314 & -0.1 \\
\hline 8. & Pyrazinamide & $\mathrm{C} 1=\mathrm{CN}=\mathrm{C}(\mathrm{C}=\mathrm{N} 1) \mathrm{C}(=\mathrm{O}) \mathrm{N}$ & 1 & 3 & 123.115 & -0.6 \\
\hline
\end{tabular}

\section{Analysis of drug-like properties}

Drug-like properties are intrinsic properties of the molecules and it is necessary to optimize the pharmacological and drug-like properties of the tested molecules. The druglike properties of ADMET screened terpenoids and the known inhibitor were examined on the basis of Lipinski's rule of five (Table 2). The data revealed that all terpenoids successfully accept Lipinski's rule of five, except for rifampicin that failed in two parameters namely, molecular weight and H-Bond acceptor.

\section{Molecular docking analyses}

\section{Identification of active pockets}

The binding site prophecy of the target was carried out using Castp to find out catalytic sites in the target molecule with the largest volumes (Table 3). The first pocket of the PKS18 (PDB ID: 1TED) has an area of 693.2 and volume of 761.625, the second identified pocket has an area of 577.8 and volume of 648.875. These identified active sites were used to identify the best ligand binding site. 
Table 3: Identified active sites of receptor PKS18 with the corresponding interacting residues.

\begin{tabular}{|c|c|c|c|c|}
\hline S. No. & Area & Volume & Interacting residues & Binding pocket \\
\hline 1. & 693.2 & 761.625 & $\begin{array}{l}\text { PRO29, THR30, THR3, VAL32, ALA33, } \\
\text { GLY136, SER164, SER166, ARG167, VAL168, } \\
\text { ASN180, GLY183, THR184, THR186, ASN187, } \\
\text { TYR188, ARG190, HIS192, MET195, VAL249, } \\
\text { ARG250, SER251, SER252, PHE253, SER254, } \\
\text { GLN255, GLU295, MET296, ASP299 }\end{array}$ & Pocket 1 \\
\hline 2. & 577.8 & 648.875 & $\begin{array}{l}\text { LEU140, THR142, GLY145, PHE146, ILE147, } \\
\text { THR142, PHE146, ILE147, GLY145, } \\
\text { ILE147, ALA148, PRO149, GLY150, } \\
\text { ASP152, VAL153, ARG167, VAL169, } \\
\text { ASN171, PHE172, MET173, THR362, } \\
\text { GLY378, PRO379, GLY380 }\end{array}$ & Pocket 2 \\
\hline
\end{tabular}

A subset of 19 screened terpenoids and first-line anti-TB drugs (rifampicin, isoniazid, ethambutol, and pyrazinamide) that fulfilled ADMET criteria and Lipinski's rule of five, were assessed on target PKS18, using protein structure-based molecular docking. To understand the mechanism underlying the binding of M.tb. PKS18 by the selected compounds and to rank the binding affinities we analyzed the docking modes of terpenoids, in the active site of M.tb. PKS18. All compounds appear to fit well in the active site pocket, but the binding affinity of four terpenoids namely, vulgarin, alisiaquinone A, 12-Deoxyphorbol-13-angelate20 -acetate, cynaropicrin were higher than that of the all standard drugs.

Negative Gibbs free energy is considered as an indicator for better binding efficiency and hence is used to determine the strength of interaction between a ligand and an enzyme. The lowest binding energy is the result of the best binding conformer at the active site of an enzyme (Xu et al., 2008). In addition, the mean of a smaller value of $\mathrm{Ki}$ is greater binding affinity and the smaller dose of drug needed in order to inhibit the activity of that enzyme. Therefore, the use of the $\mathrm{Ki}$ is helpful in designating the likelihood that a particular drug is going to inhibit a particular enzyme (Bachmann et al., 2005). The results of molecular docking studies are accorded in Table 4 , while the binding conformation of top two compounds and standard drugs is shown in Figure 3.

Data presented in Table 4 revealed that among the commercially available first-line anti-TB drugs, isoniazid exhibited the best docking energy against PKS18 with a binding affinity of $-6.00 \mathrm{kcal} / \mathrm{mol}$ followed by ethambutol $(-5.92 \mathrm{kcal} /$ mol), pyrazinamide $(-5.62 \mathrm{kcal} / \mathrm{mol})$ and rifampicin $(-1.3 \mathrm{kcal} /$ mol) Table 4.

Among the terpenoids tested, vulgarin exhibited the best binding affinity in terms of having lowest binding energy (negative Gibbs free energy, $-7.95 \mathrm{Kcal} / \mathrm{mol}$ ) with $\mathrm{Ki}$ $(1.48 \mu \mathrm{M})$, followed by alisiaquinone $\mathrm{A}(-7.86 \mathrm{Kcal} / \mathrm{mol})$, 12-Deoxyphorbol-13-angelate-20-acetate $(-7.78 \mathrm{Kcal} / \mathrm{mol})$ and Cynaropicrin $(-7.36 \mathrm{Kcal} / \mathrm{mol})$. It should be noted that the binding affinity of vulgarin for PKS18 was $\sim 1.4$ and $\sim 6.11$ fold higher than that of isoniazid and rifampicin respectively, Moreover, the inhibition constant value of vulgarin $(1.48$ $\mu \mathrm{M})$ is 28 fold and 230 fold lower as compared to first-line anti-TB drugs (with best binding affinity among tested as control) isoniazid ( $\mathrm{Ki} 40.30 \mu \mathrm{M}$ ) and rifampicin (Ki 401.02 $\mu \mathrm{M})$ respectively. In same manner inhibition constant value of alisiaquinone A $(1.75 \mu \mathrm{M})$ is 27 fold and 229 fold lower as compared to isoniazid ( $\mathrm{Ki} 40.30 \mu \mathrm{M}$ ) and rifampicin $(\mathrm{Ki}$ $401.02 \mu \mathrm{M})$ respectively. These findings indicating that a much smaller concentration of vulgarin and alisiaquinone A may be required to inhibit PKS18. Apart from vulgarin, the other three active terpenoids also showed a much better profile than the tested first-line drugs of TB in terms of binding affinity and inhibition constant. The binding affinity of these three terpenoids was multiple folds greater than that of firstline anti-TB drugs. This implies that the required doses of these compounds to inhibit the activity of this enzyme will be lower than drugs.

All the compounds (vulgarin, alisiaquinone A, 12-Deoxyphorbol-13-angelate-20-acetate, and cynaropicrin) screened in this study, have been reported to possess various biological activities. Vulgarin is one of the major phytoconstituent of Artimisia vulgaris which contains many phytoconstituents in high concentrations (Khalid et al., 2017) and exhibits a combination of anticholinergic and $\mathrm{Ca}^{2+}$ antagonist mechanisms, thus providing a pharmacological basis for its folklore use in the hyperactive gut and airways disorders, such as abdominal colic diarrhea and asthma (Khan et al., 2009). Vulgarin also exhibits significant anti-hepatotoxic activity by diminishing the higher level of serum enzymes such as serum glutamate oxaloacetate transaminase (SGOT), serum glutamate pyruvate oxaloacetate transaminase (SGPT) and alkaline phosphatase (ALP) (Verma et al., 2012). 
Table 4: Binding affinity energies and the interacting amino acids of catalytic sites of PKS 18 receptors with terpenoids and standard drugs.

\begin{tabular}{|c|c|c|c|c|c|}
\hline S. No. & Compound name & $\begin{array}{l}\text { Binding energy } \\
(\text { Kcal } / \mathbf{m o l})\end{array}$ & $\mathrm{Ki}(\mu \mathrm{M})$ & $\begin{array}{c}\text { Hydrogen-Bond Interacting } \\
\text { Amino Acids }\end{array}$ & Interacting Amino Acids \\
\hline 1. & Vulgarin & -7.95 & 1.48 & LYS318, & $\begin{array}{l}\text { VAL72, VAL219, LYS75, } \\
\text { LEU223, SER76, GLY316, } \\
\text { PRO317, ILE319, PRO282, } \\
\text { LEU281, SER278, LEU277 }\end{array}$ \\
\hline 2. & Alisiaquinone $\mathrm{A}$ & -7.86 & 1.75 & $\begin{array}{l}\text { GLY127, } \\
\text { ARG123 }\end{array}$ & $\begin{array}{l}\text { VAL360, VAL247, GLY245, } \\
\text { ILE35, GLU36, GLY37, LEU38, } \\
\text { ALA124, GLY127, LEU128, } \\
\text { LEU125, ALA126, ARG123 }\end{array}$ \\
\hline 3. & 12-Deoxyphorbol-13-angelate-20-acetate & -7.78 & 1.98 & $\begin{array}{l}\text { ASN187, } \\
\text { SER252, } \\
\text { SER164 }\end{array}$ & $\begin{array}{c}\text { ARG250, GLY183, SER251, } \\
\text { SER252, PHE253, ASN187, } \\
\text { SER166, SER164, ILE165, } \\
\text { SER162, GLY136, ILE135, } \\
\text { ALA133, MET195, HIS192, TYR188 }\end{array}$ \\
\hline 5. & Rifampicin & -1.3 & 401.02 & $\begin{array}{l}\text { SER254, } \\
\text { SER166, A } \\
\text { SN187 }\end{array}$ & $\begin{array}{l}\text { SER254, SER166, ASN187, MET195, } \\
\text { HIS192, TYR188, VAL168, } \\
\text { GLY183, ASN180, PHE253, SER164, ARG250 }\end{array}$ \\
\hline 6. & Isoniazid & -6.00 & 40.30 & $\begin{array}{l}\text { PHE146, } \\
\text { ILE147, } \\
\text { PHE172, } \\
\text { ALA148 }\end{array}$ & $\begin{array}{c}\text { VAL169, THR142, PHE146, } \\
\text { ILE147, PHE172, ALA148, } \\
\text { ASN171, GLY145, PHE109, GLY150, } \\
\text { PRO149, VAL151 }\end{array}$ \\
\hline
\end{tabular}

Alisiaquinone $\mathrm{A}$ is a bioactive compound isolated from new Caledonian deep-water sponge and has been shown to display dual activity against two enzymatic targets (plasmodial kinase Pfnek-1 and a protein farnesyl transferase) for malaria control, as well as in vitro study on different chloroquine-sensitive and -resistant strains of Plasmodium falciparum (Denis et al., 2008). 12-Deoxyphorbol-13-angelate-20-acetate belongs to the Euphorbia species and is reported to be used in folk medicine (Qi-Cheng et al., 2009). Cynaropicrin is one of the major phytoconstituents of Saussurea lappai and has been shown to possess antifeedant activity against $T$. confusum (Falko et al., 2010), as well as a strong anti-cancer activity against malignant, leukaemia and lymphoma (Hubal, 2005). The pro-apoptotic activity of Cynaropicrin on leukocyte cancer cell lines (Cho et al., 2004a) in combination with anti-inflammatory activity has been reported in the literature (Cho et al., 1998; Cho et al., 2000; Cho et al., 2004b). In addition to this, antibacterial effects have been shown by irreversible inhibition of MurA, an enzyme responsible for the first step in the cytoplasmatic biosynthesis of peptidoglycan precursors (Bachelier et al., 2006). While the compounds screened in this study have been reported to possess various biological activities, this is the first report on their activity against M.tb. PKS18.

\section{CONCLUSION}

The present study was carried out to test the efficiency of the naturally occurring terpenoids from different biological sources against the key M.tb. target PKS18 using in silico approaches. The knowledge on the molecular interactions of these terpenoids with the key enzymatic target could prove as a useful, tool for the design and development of future anti-TB drugs. Out of 672 terpenoids, 19 compounds exhibited good pharmacokinetic profile docked successfully within the active site of PKS18 and exhibited high binding affinity. The binding efficiency of the four 
screened compounds was higher than that of the commercially available first-line TB drugs including rifampicin, isoniazid, ethambutol, and pyrazinamide. Vulgarin showed the best docking profile followed by alisiaquinone A. The study presents for the first time four novel, natural compounds that are not only safe and possess drug-like properties but also hold promise to inhibit a key target enzyme of M.tb. PKS18, essential for the virulence and drug resistance. However, further work is required to gain a better insight into the structure-active site relationship to correlate the docking results with in vitro experiments.
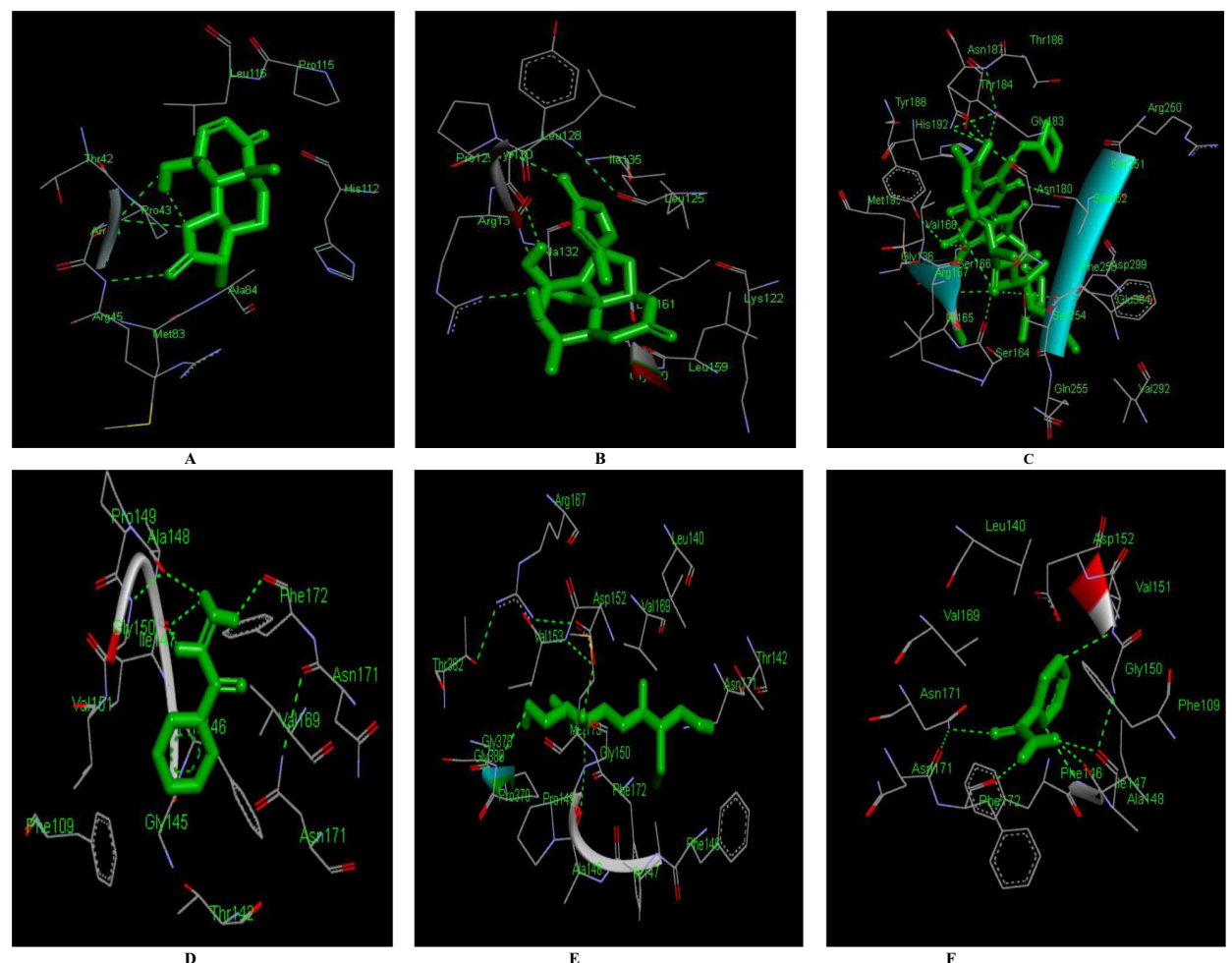

Fig. 3: Interacting amino acids of PKS 18 with (A) vulgarin, (B) alisiaquinone A, (C) rifampicin, (D) isoniazid, (E) ethambutol and (F) pyrazinamide.

\section{ACKNOWLEDGMENT}

The Integral University Communication Cell is gratefully acknowledged for quick and crisp review of the manuscript (MCN-IU/R\&D/2017-MCN000225).

\section{REFERENCES}

Anand A, Verma P, Singh AK, Ojha AK, Aldrich CC, Gokhale RS. Polyketide quinones are alternate intermediate electron carriers during mycobacterial respiration in oxygen-deficient niches. Mol Cell. 2015; 60(4):637-650.

Anchana Devi C. Docking study on Mycobacterium tuberculosis receptors AccD5 and PKS18 with selected phytochemicals. J Pharma \& Bio Sci. 2012; 4(3):01-04.

Avdeef A, Testa B. Physicochemical profiling in drug research: A brief survey. Cell Mol Life Sci, 2002; 59(10):1681-1689.

Bachelier A, Mayer R, Klein CD. Sesquiterpene lactones are potent and irreversible inhibitors of the antibacterial target enzyme MurA. Bioorganic Med Chem Lett. 2006; 16(21):5605-5609.

Bachmann KA, Lewis JD. Predicting inhibitory drug-drug interactions and evaluating drug interaction reports using inhibition constants. Ann Pharmacother. 2005; 39(6):1064-72.

Barry CE. Interpreting cell wall 'virulence factors' of Mycobacterium tuberculosis. Trends Microbiol. 2001; 9(5):237-241.

Brennan PJ. Structure, function, and biogenesis of the cell wall of Mycobacterium tuberculosis. Tuberculosis (Edinb). 2003; 83(1):91-97.

Bursulaya B, Totrov M, Abagyan R, Brooks C. Comparative Study of Several Algorithms For Flexible Ligand Docking. J Comput Aided
Mol Des. 2003; 17(11):755-763.

Centers for disease control and prevention, https://www.cdc.gov/ globalhivtb/who-we-are/events/world-tb-day/worldtbday.html (Accessed: 1 December, 2017).

Cho JY, Baik KU, Jung JH, Park MH. In vitro anti-inflammatory effects of cynaropicrin, a sesquiterpene lactone, from Saussurea lappa. Eur J Pharmacol. 2000; 398(3):399-407.

Cho JY, Kim AR, Joo HG, Kim Bh, Rhee MH, Yoo ES, Katz DR, Chain BM, Jung JH. Cynaropicrin, a sesquiterpene lactone, as a new strong regulator of CD29 and CD98 functions. Biochem Biophys Res. 2004b; 313(4):954-961.

Cho JY, Kim AR, Jung JH, Chun T, Rhee MH, Yoo ES. Cytotoxic and pro-apoptotic activities of cynaropicrin, a sesquiterpene lactone, on the viability of leukocyte cancer cell lines. Eur J Pharmacol. 2004a; 492(2):8594.

Cho JY, Park J, Yoo ES, Baik KU, Jung JH, Lee J, Park MH. Inhibitory effect of sesquiterpene lactones from Saussurea lappa on tumor necrosis factor- $\alpha$ production in murine macrophage-like cells. Planta Med. 1998; 64(7):594-597.

Denis D, Laurence M, Roselyne R, Severine C, Dominique D, Christian D, Alexis V, Frederic A, Cecile D. Alisiaquinones and Alisiaquinol, Dual Inhibitors of Plasmodium falciparum Enzyme Targets from a New Caledonian Deep Water Sponge. J Nat Prod. 2008; 71(7):1189-1192.

Ewing T, Makino S, Skillman A, Kuntz I. DOCK 4.0: search strategies for automated molecular docking of flexible molecule databases. J Comput Aided Mol Des. 2001; 15(5):411-428.

Falko P, Drijfhout, David Morgan E. 2010. Terrestrial Natural Products as Antifeedants. In: Mander L and Liu HW ed. Comprehensive 
Natural Products II, New York, Elsevier, 457-501.

Global Tuerculosis Report http://www.who.int/tb/publications/ global_report/MainText 13Nov 2017.pdf (Accessed: 3 November, 2017).

Gokhale RS, Saxena P, Chopra T, Mohanty D. Versatile polyketide enzymatic machinery for the biosynthesis of complex mycobacterial lipids. Nat Prod Rep. 2007b; 24:267-277.

Goyal A, Saxena P, Rahman A, Singh PK, Kasbekar DP, Gokhale RS, Sankaranarayanan R. Structural insights into biosynthesis of resorcinolic lipids by a type IIIpolyketide synthase in Neurospora crassa. $\mathrm{J}$ Struct Biol. 2008; 62(3):411-421.

Horie K, Tang F, Borchardt RT. Isolation and characterization of Caco-2 subclones expressing high levels of multidrug resistance protein efflux transporter. Pharm Res. 2003; 20(2):161-167.

Hubal I. 2005. Al-Mukhtarat-fi-al-Tibb. (Urdu translation by CCRUM). New Delhi, India: AYUSH Ministry of Health and Family Welfare Govt of India.

Irawin D, Kuntz, Elaine C, Meng, Brain K, Shoichet. StructureBased Molecular Design. Acc Chem Res. 1994; 27(5):117-123.

Khalid AS, Hakem AS, Hesham AM. Isolation and Characterization of the Phytoconstituents in the Aerial Parts of Wild and Home Planted Artemisia vulgaris by Gas Chromatography-Mass Spectrometry. J chem pharm res. 2017; 9(4):126-133.

Khan AU, Gilani AH. Antispasmodic and bronchodilator activities of Artemisia vulgaris are mediated through dual blockade of muscarinic receptors and calcium influx. J Ethnopharmacol. 2009; 126(3);480-486.

Lipinski CA, Lombardo F, Dominy BW, Feeney PJ. Experimental and computational approaches to estimate solubility and permeability in drug discovery and development settings. Adv Drug Deliv Rev. 2001; 46(3):3-26.

Ma X, Chen C, Yang J. Predictive model of blood-brain barrier penetration of organic compounds. Acta Pharmacol Sin. 2005; 26(4):500512.

Mangal M, Sagar P, Singh H, Raghava GP, Agarwal SM NPACT: Naturally Occurring Plant-based Anti-cancer Compound-Activity-Target database. Nucleic Acids Res. 2013; 41:1124-1129.

Morris GM, Huey R, Lindstrom W, Sanner MF, Belew RK, Goodsell DS. AutoDock4 and AutoDockTools4: automated docking with selective receptor flexibility. J Comput Chem. 2009; 30(16):2785-2791.

Qi-Cheng W, Yu-Ping T, An-Wei D, Fen-Qiang Y, Li Z, Jin-Ao D. 13C-NMR Data of Three Important Diterpenes Isolated from Euphorbia Species. Molecules. 2009; 14(11):4454-4475.

Rukmini R, Shanmugam VM, Saxena P, Gokhale RS, Sankaranarayanan R. Crystallization and preliminary X-ray crystallographic investigations of an unusual type III polyketide synthase PKS18 from Mycobacterium tuberculosis. Acta Crystallogr D Biol Crystallogr. 2004; 60(4):749-51.
Saxena P, Yadav G, Mohanty D, Gokhale RS. A new family of type III polyketide synthases in Mycobacterium tuberculosis. J Biol Chem. 2003; 278(45):44780-44790.

Sankaranarayanan R, Saxena P, Marathe UB, Gokhale RS, Shanmugam VM, Rukmini R. A novel tunnel in mycobacterial type III polyketide synthase reveals the structural basis for generating diverse metabolites. Nat Struct Mol Biol. 2004; (9):894-900.

Smith DA, Van de Waterbeemd H, Walker DK. 2001 Pharmacokinetics and Metabolism in Drug Design. Weinheim, Germany: Wiley-VCH, 61-79.

Verma A, Masoodi M, Ahmed B. Lead finding from whole plant of marrubium vulgare $\mathrm{L}$ with Hepatoprotective Potentials through in silico method. Asian Pac J Trop Biomed. 2012; 2(3):1308-1311.

Vijayalakshmia V, Ravichandiranb S, Jayakumaria A, Selvakannana, Sangeethaa G. Molecular Docking Studies of Tubulosine against Multidrug-Resistant Tuberculosis. Der Pharma Chemica. 2016; 8(19):249-256.

Woo YT. 2003. Mechanisms of action of chemical carcinogens, and their role in structure-activity relationships (SAR) analysis and risk assessment. In: Benigni R, ed. Quantitative Structure-Activity Relationship (QSAR) Models of Mutagens and Carcinogens. Boca Raton: CRC Press, $41-80$

Xiuming X, Zhijian X, Zhuo Y, Yingtao L, Wang D, Mei D, Emily JP, Weiliang Z. Key Targets and Relevant Inhibitors for the Drug Discovery of Tuberculosis. Curr Drug Targets. 2003; 14(6):676-699.

$\mathrm{Xu}$ Y, Colletier JP, Weik M, Jiang H, Moult J, Silman I, Sussman JL. Flexibility of aromatic residues in the active-site gorge of acetylcholinesterase: X-ray versus molecular dynamics. Biophys J. 2008; 95(5):2500-511.

Yamashita S, Furubayashi T, Kataoka M, Sakane T, Sezaki H, Tokuda H. Optimized Conditions for Prediction of Intestinal Drug Permeability Using Caco-2 Cells. Eur J Pharmacol. 2000; 10(3):195-204.

Zhao YH, Le J, Abraham MH, Hersey A, Eddershaw PJ, Luscombe CN, Butina D, Beck G, Sherborne B, Cooper I, Platts JA. Evaluation of human intestinal absorption data and subsequent derivation of a quantitative structure-activity relationship (QSAR) with the Abraham descriptors. J Pharm Sci. 2001; 90(6):749.

\section{How to cite this article:}

Sharma A, Islam MH, Fatima N, Upadhyay TK, Khan MKA, Dwivedi UN, Sharma R. Deciphering the Binding of Natural Terpenoids to Mycobacterium tuberculosis Type III Polyketide Synthase18 (PKS18): An In-Silico Approach. J App Pharm Sci, 2018; 8(05): 026-034. 